\title{
Argument Mining for Scholarly Document Processing: Taking Stock and Looking Ahead
}

\author{
Khalid Al-Khatib* \\ Leipzig University, Germany \\ khalid.alkhatibauni-leipzig.de
}

\author{
Tirthankar Ghosal* \\ Charles University, MFF, ÚFAL, CZ \\ ghosaldufal.mff.cuni.cz
}

\author{
Yufang Hou \\ IBM Research, Ireland \\ yhoudie.ibm. com
}

\author{
Dayne Freitag \\ SRI International, USA \\ freitageai.sri.com
}

\begin{abstract}
Argument mining targets structures in natural language related to interpretation and persuasion. Most scholarly discourse involves interpreting experimental evidence and attempting to persuade other scientists to adopt the same conclusions, which could benefit from argument mining techniques. However, While various argument mining studies have addressed student essays and news articles, those that target scientific discourse are still scarce. This paper surveys existing work in argument mining of scholarly discourse, and provides an overview of current models, data, tasks, and applications. We identify a number of key challenges confronting argument mining in the scientific domain, and suggest some possible solutions and future directions.
\end{abstract}

\section{Introduction}

Scientific papers aim to present verifiable evidence for a series of stated claims, anchoring these claims in experiments, data, and references. However, the interpretation of such objective sources of evidence is often ambiguous and subjective. Thus, much of scientific communication is essentially persuasive and uses an argumentative structure to establish the relevance, validity, and novelty of an author's main claims and conclusions (Pelclova and Weilun, 2018). This argumentation takes the form of a dialogue between the author and her readers, in which new knowledge is proposed and an attempt made to persuade the readers to accept and follow particular claims (Fahy, 2008; Hyland, 2014). However, most current research on automatic document processing ignores this argumentative context and treats statements that are persuasive, tentative, or speculative to be factual. This risks overstating the certainty of claims and hypotheses, and bypasses

*These authors contributed equally the rhetorical aspect of scientific discourse (see e.g. (Gross and Chesley, 2012)).

Computational argumentation is a recent and growing field of research concerned with the computational analysis and generation of natural language arguments and argumentative discourses. Over the past decade, this area has attracted researchers seeking to tackle different tasks including argument mining, argument quality assessment, and argument generation (for an overview, see e.g. (Stede et al., 2018)). The most studied task is argument mining, i.e., the identification of argumentative units, argument components (e.g., conclusion and premise), and structures of text documents. However, despite a wealth of Natural Language Processing (NLP) research on extracting information from scientific literature-including entity extraction (Augenstein et al., 2017; Hou et al., 2019), relation identification (Luan et al., 2018), question answering (Demner-Fushman and Lin, 2007), and summarization (Erera et al., 2019)—relatively few attempts have been made to model argumentative structures in science.

This paper argues for an increased focus of the NLP community on argument mining in scientific documents. To encourage work at the intersection of Scholarly Discourse Processing and Argument Mining, we provide a brief overview of current work in this field, and discusses the most used models, data, methods, and applications. We discuss a number of challenges in mining the argumentative structure of scientific documents and propose some promising future directions.

\section{Argumentation in Scientific Discourses}

To support future efforts on argument mining of scientific documents, we present a survey of the literature from 2000 to the present, summarized in Table 1 in the Appendix. To attempt to create a somewhat comprehensive overview, we concentrated on papers published by the NLP commu- 
nity $^{2}$. To obtain this list, we used Google Scholar (https://scholar.google.com/) to find papers on "Argumentation Mining on Scientific Papers", "Argumentation Mining on Research Papers", and "Argumentative Zoning on Scientific Papers". We also traced the references of some pivotal papers from the proceedings of Argument Mining workshops ${ }^{3}$.

For each paper, we identified the Domain of study (i.e., a specific scientific domain, full-text or abstracts), the Objectives of the work, and the Methods used. Furthermore, the papers can be categorized under four areas of study, discussed, in turn, below.

\section{Corpus Creation and New Annotation Schemes}

A number of studies propose an annotation scheme for mining argumentative discourse in the science domain. Many of these studies follow the wellknown argumentation model of Toulmin (Toulmin, 1958). Toulmin's model targets the structure of an argument, modelling it as a claim that is supported by data following some warrants, which can be supported by backing. The model has also two optional components: qualifiers and rebuttals.

Examples of the studies that adopt Toulmin's model are Green (2014) and Lauscher et al. (2018b). The former proposes the scheme of premise (i.e., data and warrant) and conclusion. The latter's scheme includes background claim, own claim, and data, which is used to annotate 40 publications from computer graphics.

Another model that is often used is that of $\operatorname{argu}$ mentation schemes (Walton et al., 2008). Argumentation schemes target the structure of an argument, where the argument is modeled as a set of propositions, i.e., a conclusion and one or more premises, with a pattern that manifests the logical inference between the conclusion and its premise. Walton et al. (2008) proposed around 60 different schemes including 'argument from cause to effect' and 'argument from example', among others. An example of this approach is Green (2015a), where ten schemes were selected and annotated in a corpus of biomedical genetics articles.

Other studies focus on identifying argumentative discourse roles, especially argumentative zones

\footnotetext{
${ }^{2}$ In this paper, we focus our research on papers related to argument mining for scholarly document processing and exclude less central topics such as citation analysis: we hope that future scholars can help augment our work with these and similar related approaches

${ }^{3}$ See https://2021.argmining.org/ and links from there for a full list of past workshops
}

(Teufel and Moens, 2002), assigning roles such as 'aim' and 'background' to large text spans (usually paragraphs). Following this approach, several corpora have been constructed for biomedical papers (Guo et al., 2011), as well as papers in chemistry, computational linguistics (Yang and Li, 2018), and agriculture (Teufel, 2014).

Inspired by the theory of Freeman (2011), some studies annotate the argumentative relations between arguments. For instance, Lauscher et al. (2018a) consider the relations of 'support', 'contradicts', and 'same claim'. Kirschner et al. (2015), in another study, consider the relations of 'support', 'attack', 'detail', and 'sequence', which were annotated in 24 articles belong to the domain of educational and developmental.

\section{Automatic Argument Unit Identification} Much work in argument mining focuses on identifying Argumentative Discourse Units (ADUs). An ADU is a text span that plays a specific role in an argument. In this way, argument unit identification resembles named entity recognition or discourse segment type identification. Green (2017b) extracted argumentative units from biomedical and biological articles using a semantic rule-based approach. Lauscher et al. (2018a) and Lauscher et al. (2018c) proposed several neural multi-task learning models based on Bi-LSTM to identify premises and conclusions. Other papers propose different approaches to identify argumentative zones, including supervised and weakly-supervised approaches with a rich set of linguistics features (e.g., (Guo et al., 2011)). Identifying the 'claim' unit is tackled in several papers such as Achakulvisut et al. (2019), which employs transfer learning on top of a discourse tagging model using a pre-trained BilSTM-CRF to identify claims in biomedical abstracts. Extracting 'evidence' has been tackled in other studies, e.g. Li et al. (2019) extracted evidence in biomedical publications with sentence-level sequential labelling, using BiLSTM-CRF and attention.

\section{Automatic Argument Structure Identification}

If unit identification resembles entity recognition, argument structure identification is akin to relation extraction: this work aims to find typed relationships between ADUs. This more challenging task has been addressed by relatively few studies: Accuosto and Saggion (2020) extend existing discourse parsing models to address this problem on 
computational linguistics abstracts and identify the argumentative discourses of computational linguistics abstracts using lexical and ELMo embeddings, while Song et al. (2019) analyze the argument structure of information science and biomedical science articles through sequential pattern mining.

Applications To date, much of the applicationoriented work has focused on scientific article summarization. An exception is Feltrim and Teufel (2004), which had the goal of developing tools for scientific writing for the computer science domain. Other efforts aim to identify claims and evidence, to enable claim-evidence based representations of collections of documents, such as (de Waard et al., 2009), (Groza et al., 2011) and (Li et al., 2021). The goal here is to allow the reader to traverse the reasoning behind a scientific claim to either experimental evidence in the paper itself, or to reasoning for data provided in cited papers. Recently, Yu et al. (2020) study the problem of correlation-tocausation exaggeration in press releases by comparing claims made in news articles and the corresponding scientific papers.

\section{Challenges}

In this section, we describe a few challenges that are relevant to argument mining in the scientific literature. Although not only specific for the scientific domain, these are hurdles that need to be faced in future research to allow progress to be made.

Argumentation Modeling As described above, various argument models have been proposed (Stede et al., 2018). The selection of which model fits scientific documents is a crucial and challenging research question.

Most previous studies in argument mining of scientific documents utilize either Toulmin's model or argumentation schemes. However, none of these models seems to be a perfect fit: Toulmin's warrants and rebuttals are not common to scholarly argumentation ${ }^{4}$, and none of the other argument schemes take the specific nature of scholarly argumentation into account. Adapting these models for use seems to be an essential step to achieve feasible annotation and identification of argument structures in scholarly discourse.

\footnotetext{
${ }^{4}$ For example, Lauscher et al. (2018b) conducted an expert annotation of the argumentative structures of a small set of scientific publications based on Toulmin's model. The annotation results show that warrant, backing, qualifier, and rebuttal are not observed in the publications.
}

Domain Knowledge Science communication encompasses a variety of domains, topics, and methodologies organized into research communities, each following its own standards regarding the structuring of documents and the arguments they contain (Weinstein, 1990). These community conventions present a barrier to understanding for nonspecialists and computational models alike. An important open question, therefore, is whether argument mining techniques must be tailored to individual scientific communities, or whether a unified model can be adapted to address domain-specific features of scientific argumentation.

Scientific Document Type Scientific communication involves a variety of document types, including reviews, methods papers, and experimental reports, among others ${ }^{5}$. Each type concentrates on specific aspects of the discussed topic and usually provides particular types of evidence.

Analogous to the previous point, an open question is whether different document types require different models, or whether they can be accommodated by a single representation and modeling approach tailored to different argument structures.

Enthymemes An enthymeme is the implicit (unstated) premise or conclusion in an argument. Because enthymemes are supposedly known by the target audience (or easily constructed using common knowledge), enthymeme are rarely a problem for humans. However, to the extent that shared knowledge is required which is not found in the document, this offers a challenge for argument mining techniques.

As an example, Green (2014) conducted a manual inspection of several arguments in the biomedical genetics research literature, showing that arguments with enthymemes are common there and suggested explicitly providing domain knowledge for reconstructing enthymemes.

Subjective Interpretation A common dilemma in argument mining is that an argumentative text may have multiple valid interpretations of its structure. This is a concern for scientific documents, where the connection between a claim and its evidence can be implicit, i.e., the author leaves this connection to the readers' interpretations.

In particular, experimental papers can follow a line of reasoning that makes e.g. 'biological sense',

\footnotetext{
${ }^{5}$ For more examples of the types, see https://coling2018. org/index.html\%3Fp=156.html
} 
i.e. where a specific experiment follows another experiment to address a potential alternate interpretation of the previous experiment. For a nonbiologist, this reasoning is unclear, and the reason for these subsequent results are generally never explicitly stated in the text.

Context-Dependence Context plays a key role in text mining in general and argument mining in particular. Scientific documents are at least as complex as other genres where argument plays a role, such as persuasive essays, to fulfil both the persuasive role and the presentation of objectivity which scientific writing demands (Vazquez Orta and Giner, 2009-11). More specifically, selecting the optimal boundaries of argumentative units in scientific documents is known to be challenging (Green, 2014; Stab et al., 2014). For instance, the distance between a claim and its premise may be particularly wide in scientific discourse, e.g., the claim which is stated in one section can be supported by a premise in a different section.

\section{Discussion}

In summary, we have provided a brief overview of current work and a summary of issues that need to be addressed to make headway in the automated argument mining for scholarly documents. We hope to have shown that more research is needed in this field to enable better representation of the persuasive aspects of scholarly communication. This can help provide a more realistic representation of how scientific knowledge is obtained, and how authors aim to persuade readers of the validity of claims. In particular, seeing scholarly discourse as a pragmatic discourse, i.e. one that humans undertake with interpersonal, as well as informative goals, can allow richer representations of the knowledge structures underlying scientific progress.

As noted, applications of argument mining in scientific discourse, such as summarization and aids to technical writing, to date have been limited to those that are relatively robust to errors, a partial consequence of the immaturity of the field. In particular, these applications are mostly insensitive to the factual content of scientific arguments. Meanwhile, a relatively mature community continues to expand models and methods for information extraction in various scientific domains, usually with no attention to the argumentative context in which the target facts are presented. Because a correct understanding and use of facts is critical to scientific understanding and progress, we see an opportunity for many innovative applications at the intersection of fact and argument. For example, models capable of determining the salience of individual facts in a domain could provide the basis for highly precise forms of scientific information retrieval, or even offer forms of automation that assist scientists in maximizing the pertinence of their experiments.

To achieve this vision at scale, the argument mining community must grapple with the problem of increasing scientific domain specialization. It is crucial that we separate the invariant features of scientific argumentation from those that vary with field and specialization, and that we investigate effective methods of cross-domain transfer. To this end, the field should seek consensus regarding how scientific argumentation should be formalized and strive for broad-coverage reference corpora annotated under guidelines optimized for high interannotator agreement.

To support these efforts, we suggest a greater collaboration between participants of the scholarly document processing and argument mining domains, with a particular focus on creating shared models and shared and accessible corpora to spur on research. We hope such conversations can commence at this workshop and others, to inspire and unite members of both communities with natural language processing and improve sharing and improving the outputs of science and scholarship.

\section{Conclusion}

This paper endeavors at promoting the collaboration between the communities of scholarly discourse processing and computational argumentation, arguing for the ultimate importance of more extensive research on argument mining in scientific documents. Particularly, we address the current contributions on argument mining for scientific documents by surveying about 40 papers that approach different aspects and tasks such as proposing annotation schemes, creating corpora, and identifying argumentative discourse units as well as argumentative relations in scientific documents. Furthermore, we describe various challenges for mining argumentative structures of scientific documents and suggest some strategic directions in order to accomplish remarkable benefits on a wide range of downstream applications such as scientific writing assistance, scientific articles summarization, and quality assessment. 


\section{References}

Pablo Accuosto and Horacio Saggion. 2019. Transferring knowledge from discourse to arguments: A case study with scientific abstracts. In Stein B, Wachsmuth H, editors. Proceedings of the 6th Workshop on Argument Mining; 2019 Aug 1; Florence, Italy. Stroudsburg: Association for Computational Linguistics; 2019. p. 41-51. ACL (Association for Computational Linguistics).

Pablo Accuosto and Horacio Saggion. 2020. Mining arguments in scientific abstracts with discourselevel embeddings. Data \& Knowledge Engineering, 129:101840.

Titipat Achakulvisut, Chandra Bhagavatula, Daniel Acuna, and Konrad Kording. 2019. Claim extraction in biomedical publications using deep discourse model and transfer learning. arXiv preprint arXiv:1907.00962.

Mohammed Alliheedi, Robert E Mercer, and Robin Cohen. 2019. Annotation of rhetorical moves in biochemistry articles. In Proceedings of the 6th Workshop on Argument Mining, pages 113-123.

Isabelle Augenstein, Mrinal Das, Sebastian Riedel, Lakshmi Vikraman, and Andrew McCallum. 2017. SemEval 2017 task 10: ScienceIE - extracting keyphrases and relations from scientific publications. In Proceedings of the 11th International Workshop on Semantic Evaluation (SemEval-2017), pages 546-555, Vancouver, Canada. Association for Computational Linguistics.

Danish Contractor, Yufan Guo, and Anna Korhonen. 2012. Using argumentative zones for extractive summarization of scientific articles. In Proceedings of COLING 2012, pages 663-678.

Dina Demner-Fushman and Jimmy Lin. 2007. Answering clinical questions with knowledge-based and statistical techniques. Computational Linguistics, 33(1):63-103.

Shai Erera, Michal Shmueli-Scheuer, Guy Feigenblat, Ora Peled Nakash, Odellia Boni, Haggai Roitman, Doron Cohen, Bar Weiner, Yosi Mass, Or Rivlin, Guy Lev, Achiya Jerbi, Jonathan Herzig, Yufang Hou, Charles Jochim, Martin Gleize, Francesca Bonin, Francesca Bonin, and David Konopnicki. 2019. A summarization system for scientific documents. In Proceedings of the 2019 Conference on Empirical Methods in Natural Language Processing and the 9th International Joint Conference on Natural Language Processing (EMNLP-IJCNLP): System Demonstrations, pages 211-216, Hong Kong, China. Association for Computational Linguistics.

Kathleen Fahy. 2008. Writing for publication: Argument and evidence. Women and Birth, 21(3):113117.
Syeed Ibn Faiz and Robert E Mercer. 2014. Extracting higher order relations from biomedical text. In Proceedings of the First Workshop on Argumentation Mining, pages 100-101.

Valéria D Feltrim and Simone Teufel. 2004. Automatic critiquing of novices' scientific writing using argumentative zoning. In Proc. AAAI spring symposium exploring affect and attitude in text.

Valéria D Feltrim, Simone Teufel, Maria Graças V das Nunes, and Sandra M Aluísio. 2006. Argumentative zoning applied to critiquing novices' scientific abstracts. In Computing Attitude and Affect in Text: Theory and Applications, pages 233-246. Springer.

J. Freeman. 2011. Argument structure: Representation and theory. In Argumentation Library.

Heather Graves, Roger Graves, Robert E Mercer, and Mahzereen Akter. 2014. Titles that announce argumentative claims in biomedical research articles. In Proceedings of the First Workshop on Argumentation Mining, pages 98-99.

Nancy Green. 2014. Towards creation of a corpus for argumentation mining the biomedical genetics research literature. In Proceedings of the first workshop on argumentation mining, pages 11-18.

Nancy Green. 2015a. Identifying argumentation schemes in genetics research articles. In Proceedings of the 2nd Workshop on Argumentation Mining, pages 12-21.

Nancy Green. 2017a. Manual identification of arguments with implicit conclusions using semantic rules for argument mining. In Proceedings of the 4th Workshop on Argument Mining, pages 73-78.

Nancy Green. 2018a. Proposed method for annotation of scientific arguments in terms of semantic relations and argument schemes. In Proceedings of the 5th Workshop on Argument Mining, pages 105-110.

Nancy L Green. 2015b. Annotating evidence-based argumentation in biomedical text. In 2015 IEEE International Conference on Bioinformatics and Biomedicine (BIBM), pages 922-929. IEEE.

Nancy L Green. 2017b. Argumentation mining in scientific discourse. In CMNA@ICAIL, pages 7-13.

Nancy L Green. 2018b. Towards mining scientific discourse using argumentation schemes. Argument \& Computation, 9(2):121-135.

A. Gross and Paula Chesley. 2012. Hedging, stance and voice in medical research articles.

Tudor Groza, Siegfried Handschuh, and Stefan Decker. 2011. Capturing rhetoric and argumentation aspects within scientific publications. In Journal on data semantics $X V$, pages $1-36$. Springer. 
Yufan Guo, Anna Korhonen, and Thierry Poibeau. 2011. A weakly-supervised approach to argumentative zoning of scientific documents. In Empirical Methods in Natural language Processing (EMNLP).

Yufan Guo, Ilona Silins, Roi Reichart, and Anna Korhonen. 2012. Crab reader: A tool for analysis and visualization of argumentative zones in scientific literature. In Proceedings of COLING 2012: Demonstration Papers, pages 183-190.

Yufang Hou, Charles Jochim, Martin Gleize, Francesca Bonin, and Debasis Ganguly. 2019. Identification of tasks, datasets, evaluation metrics, and numeric scores for scientific leaderboards construction. In Proceedings of the 57th Annual Meeting of the Association for Computational Linguistics, pages 5203-5213, Florence, Italy. Association for Computational Linguistics.

Hospice Houngbo and Robert E Mercer. 2014. An automated method to build a corpus of rhetoricallyclassified sentences in biomedical texts. In Proceedings of the first workshop on argumentation mining, pages 19-23.

Ken Hyland. 2014. Introductory chapter:dialogue, community and persuasion in research writing. In Luz Gil-Salom and Carmen Soler-Monreal, editors, Dialogicity in Written Specialised Genres, Dialogicity in Written Specialised Genres, pages 1-20. John Benjamins.

Christian Kirschner, Judith Eckle-Kohler, and Iryna Gurevych. 2015. Linking the thoughts: Analysis of argumentation structures in scientific publications. In Proceedings of the 2nd Workshop on Argumentation Mining, pages 1-11.

Anne Lauscher, Goran Glavaš, and Kai Eckert. 2018a. Arguminsci: A tool for analyzing argumentation and rhetorical aspects in scientific writing. Association for Computational Linguistics.

Anne Lauscher, Goran Glavaš, and Simone Paolo Ponzetto. 2018b. An argument-annotated corpus of scientific publications. In Proceedings of the 5th Workshop on Argument Mining, pages 40-46.

Anne Lauscher, Goran Glavaš, Simone Paolo Ponzetto, and Kai Eckert. 2018c. Investigating the role of argumentation in the rhetorical analysis of scientific publications with neural multi-task learning models. In Proceedings of the 2018 Conference on Empirical Methods in Natural Language Processing, pages 3326-3338.

Xiangci Li, Gully Burns, and Nanyun Peng. 2019. Scientific discourse tagging for evidence extraction. arXiv e-prints, pages arXiv-1909.

Xiangci Li, Gully Burns, and Nanyun Peng. 2021. Scientific discourse tagging for evidence extraction. In Proceedings of the 16th Conference of the European Chapter of the Association for Computational Linguistics: Main Volume, pages 2550-2562, Online. Association for Computational Linguistics.
Yi Luan, Luheng He, Mari Ostendorf, and Hannaneh Hajishirzi. 2018. Multi-task identification of entities, relations, and coreference for scientific knowledge graph construction. In Proceedings of the 2018 Conference on Empirical Methods in Natural Language Processing, pages 3219-3232, Brussels, Belgium. Association for Computational Linguistics.

Jana Pelclova and Lu Wei-lun. 2018. Persuasion in public discourse: cognitive and functional perspectives. Discourse approaches to politics, society, and culture.

José María González Pinto, Serkan Celik, and WolfTilo Balke. 2019. Learning to rank claim-evidence pairs to assist scientific-based argumentation. In International Conference on Theory and Practice of Digital Libraries, pages 41-55. Springer.

Ningyuan Song, Hanghang Cheng, Huimin Zhou, and Xiaoguang Wang. 2019. Argument structure mining in scientific articles: a comparative analysis. In 2019 ACM/IEEE Joint Conference on Digital Libraries (JCDL), pages 339-340. IEEE.

Christian Stab, Christian Kirschner, Judith EckleKohler, and Iryna Gurevych. 2014. Argumentation mining in persuasive essays and scientific articles from the discourse structure perspective. In Proceedings of the Workshop on Frontiers and Connections between Argumentation Theory and Natural Language Processing, Forli-Cesena, Italy, July 2125, 2014, volume 1341 of CEUR Workshop Proceedings. CEUR-WS.org.

M. Stede, J. Schneider, and G. Hirst. 2018. Argumentation Mining. Synthesis Lectures on Human Language Technologies. Morgan \& Claypool Publishers.

Manfred Stede, Maite Taboada, and Debopam Das. 2017. Annotation guidelines for rhetorical structure. Manuscript. University of Potsdam and Simon Fraser University.

Simone Teufel. 2014. Scientific argumentation detection as limited-domain intention recognition. In $\operatorname{ArgNLP.}$

Simone Teufel and Marc Moens. 1999. Discourselevel argumentation in scientific articles: human and automatic annotation. In Towards Standards and Tools for Discourse Tagging.

Simone Teufel and Marc Moens. 2002. Summarizing scientific articles: experiments with relevance and rhetorical status. Computational linguistics, 28(4):409-445.

Stephen E. Toulmin. 1958. The Uses of Argument. Cambridge University Press.

Ignacio Vazquez Orta and Diana Giner. 2009-11. Writing with conviction: the use of boosters in modelling persuasion in academic discourses. 
Anita de Waard, S Buckingham Shum, Annamaria Carusi, Jack Park, Matthias Samwald, and Ágnes Sándor. 2009. Hypotheses, evidence and relationships: The hyper approach for representing scientific knowledge claims.

Douglas Walton, Chris Reed, and Fabrizio Macagno. 2008. Argumentation Schemes. Cambridge University Press.

Mark Weinstein. 1990. Towards an account of argumentation in science. Argumentation, 4(3):269298.

An Yang and Sujian Li. 2018. SciDTB: Discourse dependency TreeBank for scientific abstracts. In Proceedings of the 56th Annual Meeting of the Association for Computational Linguistics (Volume 2: Short Papers), pages 444-449, Melbourne, Australia. Association for Computational Linguistics.

Antonio Jimeno Yepes, James G Mork, and Alan R Aronson. 2013. Using the argumentative structure of scientific literature to improve information access. In Proceedings of the 2013 Workshop on Biomedical Natural Language Processing, pages 102-110.

Bei Yu, Jun Wang, Lu Guo, and Yingya Li. 2020 Measuring correlation-to-causation exaggeration in press releases. In Proceedings of the 28th International Conference on Computational Linguistics, pages 4860-4872, Barcelona, Spain (Online). International Committee on Computational Linguistics.

\section{A Appendix}

Please follow in the next page. 
Table 1: Argumentation Mining Literature on Scientific Discourse

\begin{tabular}{|c|c|c|c|c|}
\hline Reference & Domain & Objectives & Methods & Additional Contribution \\
\hline \multicolumn{5}{|c|}{ Manual Argument Analysis } \\
\hline Green $(2015 b)$ & $\begin{array}{l}\text { Biomedical } \\
\text { articles }\end{array}$ & $\begin{array}{l}\text { Analyzed evidence based arguments } \\
\text { in four full-text articles on genetic } \\
\text { variants that may cause human health } \\
\text { problems and created a preliminary } \\
\text { catalog of argumentation schemes }\end{array}$ & & \\
\hline Green (2017a) & $\begin{array}{l}\text { Biomedical } \\
\text { articles }\end{array}$ & $\begin{array}{l}\text { Evaluate human analysts' ability to } \\
\text { identify the argumentation scheme } \\
\text { and premises of an argument having } \\
\text { an implicit conclusion }\end{array}$ & & \\
\hline Green (2018b) & $\begin{array}{l}\text { Biomedical } \\
\text { research articles }\end{array}$ & $\begin{array}{l}\text { Explores how arguments in a research } \\
\text { article occur within a narrative of sci- } \\
\text { entific discovery and how they are re- } \\
\text { lated to each other }\end{array}$ & & \\
\hline Green (2018a) & $\begin{array}{l}\text { Biomedical } \\
\text { Genetics articles }\end{array}$ & $\begin{array}{l}\text { Provide a method for semantic rep- } \\
\text { resentation of arguments that can be } \\
\text { used in empirical studies of scientific } \\
\text { discourse as well as to support appli- } \\
\text { cations such as argument mining }\end{array}$ & & \\
\hline $\begin{array}{lll}\text { Graves } & \text { et } & \text { al. } \\
(2014) & & \end{array}$ & $\begin{array}{l}\text { Biomedical } \\
\text { articles }\end{array}$ & $\begin{array}{l}\text { Analyses article title as a potential } \\
\text { source of claims and finds that fre- } \\
\text { quency of verbs in titles of experimen- } \\
\text { tal research articles has increased over } \\
\text { time }\end{array}$ & & \\
\hline \multicolumn{5}{|c|}{ Corpus Creation and New Annotation Schemes } \\
\hline Green (2014) & $\begin{array}{l}\text { Biomedical } \\
\text { Genetics articles }\end{array}$ & $\begin{array}{l}\text { Argument annotation scheme: } \\
\text { Premise (Data, Warrant) and Conclu- } \\
\text { sion }\end{array}$ & & $\begin{array}{l}\text { Theoretical challenges to cre- } \\
\text { ate an argument corpora }\end{array}$ \\
\hline Green (2015a) & $\begin{array}{l}\text { Biomedical } \\
\text { Genetics articles }\end{array}$ & $\begin{array}{l}\text { Identification of argumentation } \\
\text { schemes with specification of ten } \\
\text { semantically distinct argumentation } \\
\text { schemes }\end{array}$ & & $\begin{array}{l}\text { Annotation guidelines for ar- } \\
\text { gumentation corpora }\end{array}$ \\
\hline $\begin{array}{l}\text { Teufel and Moens } \\
\text { (1999) }\end{array}$ & $\begin{array}{l}\text { Chemistry, } \begin{array}{l}\text { Com- } \\
\text { putational } \\
\text { guistics }\end{array} \\
\end{array}$ & $\begin{array}{l}\text { Detect argument zones in scientific ar- } \\
\text { ticles }\end{array}$ & $\begin{array}{l}\text { Proposed a scheme and annotated } \\
15 \text { argument zone categories for } 39 \\
\text { papers (5,374 sentences) }\end{array}$ & \\
\hline $\begin{array}{l}\text { Kirschner et al. } \\
(2015)\end{array}$ & $\begin{array}{l}\text { Scientific articles } \\
\text { (Educational and } \\
\text { Developmental } \\
\text { Psychology) }\end{array}$ & $\begin{array}{l}\text { New annotation scheme to identify } \\
\text { argumentative relations - support, at- } \\
\text { tack, detail, sequence }\end{array}$ & & $\begin{array}{l}\text { Study of the annotation strat- } \\
\text { egy across } 24 \text { articles, an anno- } \\
\text { tation tool, a new graph-based } \\
\text { inter-annotation measure }\end{array}$ \\
\hline $\begin{array}{l}\text { Lauscher et al. } \\
\text { (2018b) }\end{array}$ & $\begin{array}{l}\text { Computer Graph- } \\
\text { ics scientific pub- } \\
\text { lications }\end{array}$ & $\begin{array}{l}\text { Proposed a new argument-annotated } \\
\text { dataset of scientific publications }\end{array}$ & $\begin{array}{l}\text { Adapted Toulmin's model for } \\
\text { argumentative components: Back- } \\
\text { ground Claim, Own Claim, Data. } \\
\text { Relation between argumentative } \\
\text { components: support, contradicts, } \\
\text { same claim }\end{array}$ & $\begin{array}{l}\text { Investigation on link between } \\
\text { argumentative nature of scien- } \\
\text { tific publications and rhetori- } \\
\text { cal aspects such as discourse } \\
\text { categories or citation contexts. }\end{array}$ \\
\hline $\begin{array}{l}\text { Alliheedi et al. } \\
\text { (2019) }\end{array}$ & $\begin{array}{l}\text { Biochemistry arti- } \\
\text { cles }\end{array}$ & $\begin{array}{l}\text { Determine rhetorical moves in the ar- } \\
\text { gument structure of biomedical arti- } \\
\text { cles }\end{array}$ & $\begin{array}{l}\text { Annotated method sections of } 105 \\
\text { text files based on a new annotation } \\
\text { scheme for identifying the struc- } \\
\text { tured representation of knowledge } \\
\text { in a set of sentences describing the } \\
\text { experimental procedures }\end{array}$ & \\
\hline Guo et al. (2012) & $\begin{array}{l}\text { Biomedical } \\
\text { papers }\end{array}$ & $\begin{array}{l}\text { Introduce a tool for analysis and visu- } \\
\text { alizing argument structure (based on } \\
\text { AZ), and also facilitate expert AZ an- } \\
\text { notation }\end{array}$ & $\begin{array}{l}\text { Used HTML, JavaScript, PHP, } \\
\text { XML for the annotation tool; SVM } \\
\text { classifier using features from Guo } \\
\text { et al. (2011) }\end{array}$ & $\begin{array}{l}\text { Interactive annotation via ac- } \\
\text { tive learning; CRAB Reader } \\
\text { allows user to define AZ } \\
\text { schemes; AZ can be per- } \\
\text { formed on each word, sen- } \\
\text { tence, paragraph, document } \\
\text { level }\end{array}$ \\
\hline $\begin{array}{l}\text { Yang and } \mathrm{Li} \\
(2018)\end{array}$ & $\begin{array}{l}\text { Scientific ab- } \\
\text { stracts from ACL } \\
\text { Anthology }\end{array}$ & 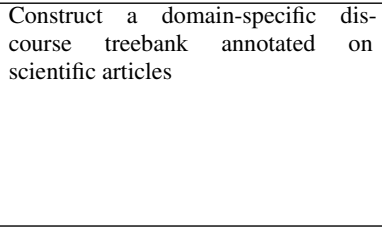 & $\begin{array}{l}798 \text { segmented abstracts were la- } \\
\text { belled by } 5 \text { annotators in } 6 \text { months. } \\
506 \text { abstracts were annotated more } \\
\text { than twice separately by different } \\
\text { annotators. In total, SciDTB con- } \\
\text { tains } 798 \text { unique abstracts with } 63 \% \\
\text { labelled more than once and } 18,978 \\
\text { discourse relations. }\end{array}$ & $\begin{array}{l}\text { Provide several baselines for } \\
\text { scientific discourse depen- } \\
\text { dency tree parsing }\end{array}$ \\
\hline \multicolumn{5}{|c|}{ Automatic Argument Unit Identification } \\
\hline Green $(2017 b)$ & $\begin{array}{l}\text { Biomedical, Bio- } \\
\text { logical articles }\end{array}$ & Argumentation extraction & Semantic rule-based approach & $\begin{array}{l}\text { Demonstrates the need for } \\
\text { a richer model of inter- } \\
\text { argument relationships in } \\
\text { biomedical/biological re- } \\
\text { search articles. }\end{array}$ \\
\hline
\end{tabular}




\begin{tabular}{|c|c|c|c|c|}
\hline Reference & Domain & Objectives & Methods & Additional Contribution \\
\hline $\begin{array}{l}\text { Lauscher et al. } \\
(2018 \mathrm{a})\end{array}$ & $\begin{array}{l}\text { Computer Graphics } \\
\text { scientific publica- } \\
\text { tions }\end{array}$ & $\begin{array}{l}\text { A toolkit for rhetorical analysis of } \\
\text { argument component identification, } \\
\text { discourse role classification, subjec- } \\
\text { tive aspect classification, citation } \\
\text { context classification, summary rel- } \\
\text { evance classification }\end{array}$ & $\begin{array}{l}\text { Token-level sequence la- } \\
\text { belling, sentence-level classifi- } \\
\text { cation using Bi-1STM }\end{array}$ & $\begin{array}{l}\text { Command-line tool, RESTful API, } \\
\text { web application }\end{array}$ \\
\hline $\begin{array}{l}\begin{array}{l}\text { Lauscher et al. } \\
(2018 \mathrm{c})\end{array} \\
\end{array}$ & $\begin{array}{l}\text { Computer } \text { Graphics } \\
\text { scientific publica- } \\
\text { tions }\end{array}$ & $\begin{array}{l}\text { Proposed two neural multi-task } \\
\text { learning (MTL) models for argu- } \\
\text { mentative analysis based on the } \\
\text { tasks in (Lauscher et al., 2018a) }\end{array}$ & $\begin{array}{l}\text { Bi-LSTM based simple MTL } \\
\text { model for sentence-level clas- } \\
\text { sification, hierarchical MTL } \\
\text { for sequence labelling }\end{array}$ & $\begin{array}{l}\text { Adapted Toulmin's model for } \\
\text { argumentative components: Back- } \\
\text { ground Claim, Own Claim, Data. } \\
\text { Relation between argumentative } \\
\text { components: support, contradicts, } \\
\text { same claim }\end{array}$ \\
\hline Teufel (2014) & $\begin{array}{l}\text { Chemistry, Compu- } \\
\text { tational Linguistics, } \\
\text { Agriculture }\end{array}$ & $\begin{array}{l}\text { Views scientific argumentation de- } \\
\text { tection as limited-domain intent } \\
\text { recognition }\end{array}$ & $\begin{array}{l}\text { Model based on recognition of } \\
28 \text { rhetorical moves in text }\end{array}$ & \\
\hline Guo et al. (2011) & $\begin{array}{l}\text { Biomedical ab- } \\
\text { stracts }\end{array}$ & $\begin{array}{l}\text { Investigating a weakly-supervised } \\
\text { approach for AZ detection when a } \\
\text { limited amount of training data is } \\
\text { available }\end{array}$ & $\begin{array}{l}\text { Features like location, word } \\
\text { bi-gram, verb, verb cues, } \\
\text { PoS, grammatical relations, } \\
\text { subj/obj, voice are used with } \\
\text { ASVM, ASSVM, TSVM, } \\
\text { SSCRF }\end{array}$ & $\begin{array}{l}\text { Conclusion that location of AZs are } \\
\text { super important, directions to facili- } \\
\text { tate easy porting of AZ schemes to } \\
\text { new NLP tasks and domains }\end{array}$ \\
\hline Li et al. (2019) & $\begin{array}{l}\text { Biomedical publica- } \\
\text { tions }\end{array}$ & $\begin{array}{l}\text { Automatic evidence extraction us- } \\
\text { ing scientific discourse tagging } \\
\text { based on classification by de Waard } \\
\text { et al. (2009) }\end{array}$ & $\begin{array}{l}\text { sentence-level sequential la- } \\
\text { belling using BiLSTM-CRF + } \\
\text { Attention }\end{array}$ & $\begin{array}{l}\text { Leveraging scientific discourse tag- } \\
\text { ging for evidence fragment detec- } \\
\text { tion }\end{array}$ \\
\hline $\begin{array}{l}\text { Achakulvisut et al. } \\
\text { (2019) }\end{array}$ & $\begin{array}{l}\text { Biomedical ab- } \\
\text { stracts }\end{array}$ & Automated claim extraction & $\begin{array}{l}\text { Neural discourse tagging } \\
\text { model based on a pre-trained } \\
\text { BilSTM+CRF followed by } \\
\text { transfer learning and fine } \\
\text { tuning on a expert annotated } \\
\text { dataset }\end{array}$ & $\begin{array}{l}\text { New dataset of } 1,500 \text { expert- } \\
\text { annotated biomedical abstracts } \\
\text { indicating whether the sentence } \\
\text { presents a scientific claim. }\end{array}$ \\
\hline $\begin{array}{l}\text { Houngbo and } \\
\text { Mercer (2014) }\end{array}$ & Biomedical articles & $\begin{array}{l}\text { Identify the components of IMRaD } \\
\text { rhetorical structure in biomedical } \\
\text { papers }\end{array}$ & $\begin{array}{l}\text { Applied a few heuristics to } \\
\text { construct a corpus and used } \\
\text { machine learning techniques } \\
\text { (Naive Bayes and SVM) } \\
\text { to classify sentences into } \\
\text { Method,Result or Conclusion }\end{array}$ & \\
\hline Pinto et al. (2019) & Biomedical papers & $\begin{array}{l}\text { Claim-evidence matching as a } \\
\text { learning to rank problem where } \\
\text { goal is to find evidence in the } \\
\text { form of a paper to make a natural } \\
\text { language claim appear credible; to } \\
\text { assist scientific argumentation }\end{array}$ & $\begin{array}{l}\text { Rhetoric Classification Task } \\
\text { and Claim-Evidence Rank } \\
\text { Task using NB-BoW, SVM- } \\
\text { BoW, CNN on data from } \\
\text { a Wikipedia dump with } \\
\text { word2vec trained on PubMed } \\
\text { Central UMLS, SemMedDB } \\
\text { databases }\end{array}$ & $\begin{array}{l}\text { Augmenting "prestige" meta-data } \\
\text { features for a paper improved per- } \\
\text { formance, to rank claim-evidence } \\
\text { pairs, a model should account for } \\
\text { other semantic properties beyond } \\
\text { simple content-matching }\end{array}$ \\
\hline $\begin{array}{l}\text { Faiz and Mercer } \\
\text { (2014) }\end{array}$ & Biomedical papers & $\begin{array}{l}\text { Extraction of connections or } \\
\text { "higher order relations" between } \\
\text { biomedical relations (relationship } \\
\text { between biomedical entities). The } \\
\text { higher order relation conveys a } \\
\text { causal sense, which indicates that } \\
\text { the latter relation causes the earlier } \\
\text { one. }\end{array}$ & $\begin{array}{l}\text { In the first stage, the au- } \\
\text { thors use a discourse relation } \\
\text { parser to extract the explicit } \\
\text { discourse relations from text. } \\
\text { In the second stage, the au- } \\
\text { thors analyze each extracted } \\
\text { explicit discourse relation to } \\
\text { determine whether it can pro- } \\
\text { duce a higher order relation. }\end{array}$ & $\begin{array}{l}\text { Pilot evaluation on AIMed corpus } \\
\text { for protein-protein interaction pre- } \\
\text { diction: identify the full argument } \\
\text { extent which contain the biomedi- } \\
\text { cal entities }\end{array}$ \\
\hline Yepes et al. (2013) & $\begin{array}{l}\text { MEDLINE/PubMed } \\
\text { abstracts }\end{array}$ & $\begin{array}{l}\text { An evaluation of several learning } \\
\text { algorithms to label abstract text } \\
\text { with argumentative labels, based } \\
\text { on structured abstracts available in } \\
\text { MEDLINE/PubMed }\end{array}$ & $\begin{array}{l}\text { Naive Bayes, SVM, Lo- } \\
\text { gistic Legression, CRF, } \\
\text { AdaBoostM1 as classifiers for } \\
\text { the argumentation labels on } \\
\text { abstract text. In addition to } \\
\text { textual features, the position } \\
\text { of the sentence or paragraph } \\
\text { from the beginning of the } \\
\text { abstract is used }\end{array}$ & $\begin{array}{l}\text { A data set to compare and evalu- } \\
\text { ate GeneRIF indexing approaches. } \\
\text { The sentence annotation are: Ex- } \\
\text { pression, Function, Isolation, Non- } \\
\text { GeneRIF, Other, Reference, and } \\
\text { Structure on MEDLINE articles. }\end{array}$ \\
\hline \multicolumn{5}{|c|}{ Automatic Argument Structure Identification } \\
\hline Stab et al. (2014) & Scientific articles & $\begin{array}{l}\text { Identification of argumentation } \\
\text { structures }\end{array}$ & $\begin{array}{l}\text { Argument unit identification } \\
\text { and relation extraction }\end{array}$ & $\begin{array}{l}\text { An evaluation dataset of } 20 \text { scien- } \\
\text { tific full-texts annotated with argu- } \\
\text { ment relations 'support', 'attack', } \\
\text { 'sequence' }\end{array}$ \\
\hline $\begin{array}{l}\begin{array}{l}\text { Feltrim et } \\
(2006)\end{array} \\
\end{array}$ & $\begin{array}{l}\text { Brazilian PhD The- } \\
\text { ses }\end{array}$ & $\begin{array}{l}\text { A system to detect argumentative } \\
\text { structures in text }\end{array}$ & $\begin{array}{l}\text { The annotation scheme has } \\
\text { the following rhetorical cate- } \\
\text { gories: Background, Gap, Pur- } \\
\text { pose, Methodology, Results, } \\
\text { Conclusion and Outline. A } \\
\text { Naive Bayes classifier to iden- } \\
\text { tify the argumentative units }\end{array}$ & $\begin{array}{l}\text { Porting of Argumentative Zoning } \\
\text { (AZ) from English to Portuguese. A } \\
\text { pilot system to demonstrate the ef- } \\
\text { fectiveness of AZ for a critiquing } \\
\text { tool to support academic writing }\end{array}$ \\
\hline $\begin{array}{l}\text { Accuosto and Sag- } \\
\text { gion }(2020)\end{array}$ & $\begin{array}{l}\text { Computational } \\
\text { linguistics abstracts }\end{array}$ & $\begin{array}{l}\text { Argument unit identification and re- } \\
\text { lation extraction }\end{array}$ & $\begin{array}{l}\text { Explore two transfer learning } \\
\text { approaches in which discourse } \\
\text { parsing is used as an auxiliary } \\
\text { task when training argument } \\
\text { mining models }\end{array}$ & $\begin{array}{l}\text { Propose a new annotation schema } \\
\text { and use it to augment a corpus of } \\
\text { computational linguistics abstracts } \\
\text { that had previously been annotated } \\
\text { with discourse units and relations }\end{array}$ \\
\hline Song et al. (2019) & $\begin{array}{l}\text { Information Science } \\
\text { and Biomedical arti- } \\
\text { cles }\end{array}$ & $\begin{array}{l}\text { Apply sequential pattern mining } \\
\text { to analyse the common argument } \\
\text { structure in two scientific domains } \\
\text { (Information science and biomedi- } \\
\text { cal science) }\end{array}$ & & \\
\hline
\end{tabular}




\begin{tabular}{|c|c|c|c|c|}
\hline Reference & Domain & Objectives & Methods & Additional Contribution \\
\hline \multicolumn{5}{|c|}{ Applications } \\
\hline $\begin{array}{l}\text { Accuosto and Sag- } \\
\text { gion (2019) }\end{array}$ & $\begin{array}{l}\text { Computational } \\
\text { Linguistics ab- } \\
\text { stracts }\end{array}$ & $\begin{array}{l}\text { Leverage existing discourse parsing } \\
\text { RST annotations (Stede et al., 2017) } \\
\text { to identify argumentative components } \\
\text { and relations }\end{array}$ & $\begin{array}{l}\text { Transfer learning to improve the } \\
\text { performance of argument mining } \\
\text { tasks trained with a small corpus of } \\
60 \text { abstracts by leveraging the dis- } \\
\text { course annotations available in the } \\
\text { full SciDTB () corpus; sequence la- } \\
\text { belling task with dependency-based } \\
\text { word embeddings, contextualized } \\
\text { ElMo, RST encodings, GloVe }\end{array}$ & $\begin{array}{l}\text { Enrich a subset of SciDTB } \\
\text { with additional layer of ar- } \\
\text { gumentation, EDUs as mini- } \\
\text { mal span for annotation, pi- } \\
\text { lot task to predict accep- } \\
\text { tance/rejection using automat- } \\
\text { ically identified argumentative } \\
\text { components and relations }\end{array}$ \\
\hline $\begin{array}{l}\text { Contractor et al. } \\
\text { (2012) }\end{array}$ & $\begin{array}{l}\text { Biomedical } \\
\text { papers }\end{array}$ & $\begin{array}{l}\text { Leveraging on AZ features for extrac- } \\
\text { tive summarization of scientific arti- } \\
\text { cles }\end{array}$ & $\begin{array}{l}\text { Used AZ categories as features in fi- } \\
\text { nal sentence selection process + ad- } \\
\text { ditionally used verbs, tf-idf, citation } \\
\text { and reference occurrences, locative } \\
\text { features for classification to gener- } \\
\text { ate initial set of candidate sentences. } \\
\text { Then performed k-Means cluater- } \\
\text { ing to group similar sentences and } \\
\text { select the centroid from each group } \\
\text { to generate the summary (redun- } \\
\text { dancy elimination) }\end{array}$ & $\begin{array}{l}\text { Demonstrated the efficacy of } \\
\text { weakly-supervised AZ classi- } \\
\text { fier for less training data by } \\
\text { Guo et al. (2011) for scientific } \\
\text { article summary extraction }\end{array}$ \\
\hline $\begin{array}{l}\text { Teufel and Moens } \\
\text { (2002) }\end{array}$ & $\begin{array}{l}\text { Computational } \\
\text { Linguistics papers }\end{array}$ & $\begin{array}{l}\text { Summarize scientific articles by con- } \\
\text { centrating on the rhetorical status of } \\
\text { statements in an article }\end{array}$ & $\begin{array}{l}\text { Developed an algorithm to select } \\
\text { content from articles and clas- } \\
\text { sify them into rhetorical cate- } \\
\text { gories which integrate argumenta- } \\
\text { tion structure in scientific papers }\end{array}$ & \\
\hline $\begin{array}{l}\text { Feltrim and Teufel } \\
\text { (2004) }\end{array}$ & $\begin{array}{l}\text { Brazilian } \mathrm{PhD} \\
\text { Theses in Com- } \\
\text { puter Science }\end{array}$ & $\begin{array}{l}\text { Integrated Argumentative Zoning into } \\
\text { an automatic Critiquing Tool for Sci- } \\
\text { entific Writing in Portuguese (SciPo) }\end{array}$ & $\begin{array}{l}\text { Implemented a set of } 7 \text { features, de- } \\
\text { rived from the } 16 \text { used by (Teufel } \\
\text { and Moens, 2002), Naive Bayes as } \\
\text { the classifier }\end{array}$ & $\begin{array}{l}\text { Port the feature detection stage } \\
\text { of AZ from English to Por- } \\
\text { tuguese, a human annotation } \\
\text { experiment to verify the re- } \\
\text { producibility of the annotation } \\
\text { scheme, intrinsic evaluation of } \\
\text { AZ-part of SciPo }\end{array}$ \\
\hline $\begin{array}{lll}\text { Groza } & \text { et } & \text { al. } \\
(2011) & & \end{array}$ & $\begin{array}{l}\text { Production and } \\
\text { Manufacturing, } \\
\text { Biomedical, } \\
\text { Law/Legal }\end{array}$ & $\begin{array}{l}\text { The authors present SALT (Semanti- } \\
\text { cally Annotated LATEX), a semantic } \\
\text { authoring framework that enables the } \\
\text { externalization of the argumentation } \\
\text { and rhetoric captured in scientific pub- } \\
\text { lication's content. }\end{array}$ & $\begin{array}{l}\text { The annotation framework is a lay- } \\
\text { ered organization of three ontolo- } \\
\text { gies: the Document Ontology - cap- } \\
\text { turing the linear structure of the } \\
\text { publication, the Rhetorical Ontol- } \\
\text { ogy - modeling the rhetorical and } \\
\text { argumentation, and the Annotation } \\
\text { Ontology - linking the rhetoric and } \\
\text { argumentation to the publication's } \\
\text { structure and content. }\end{array}$ & $\begin{array}{l}\text { A LATEX and MS-Word plu- } \\
\text { gin for semantic annotation of } \\
\text { scientific publications as per } \\
\text { SALT scheme }\end{array}$ \\
\hline $\begin{array}{l}\text { de Waard et al. } \\
\text { (2009) }\end{array}$ & & $\begin{array}{l}\text { Proposal to extract knowledge from } \\
\text { articles to allow the construction of } \\
\text { a system where a specific scientific } \\
\text { claim is connected, through trails of } \\
\text { meaningful relationships, to experi- } \\
\text { mental evidence. To improve ac- } \\
\text { cess to collections of scientific papers } \\
\text { represented as networks of collection } \\
\text { of claims that have a defined epis- } \\
\text { temic value, with links to experimen- } \\
\text { tal evidence and argumentative rela- } \\
\text { tionships to other statements and ev- } \\
\text { idence. The authors coin this concep- } \\
\text { tual approach 'Hypotheses, Evidence } \\
\text { and Relationships' (HypER). }\end{array}$ & & \\
\hline Yu et al. (2020) & $\begin{array}{l}\text { PubMed papers } \\
\text { and news articles }\end{array}$ & Study exaggeration in press releases & $\begin{array}{l}\text { Developed a new corpus and trained } \\
\text { models that can identify causal } \\
\text { claims in the main statements in } \\
\text { a press release. By comparing } \\
\text { the claims made in a press re- } \\
\text { lease with the corresponding claims } \\
\text { in the original research paper, the } \\
\text { authors found that } 22 \% \text { of press } \\
\text { releases made exaggerated causal } \\
\text { claims from correlational findings } \\
\text { in observational studies. }\end{array}$ & \\
\hline Li et al. (2021) & $\begin{array}{l}\text { Biomedical } \\
\text { papers }\end{array}$ & $\begin{array}{l}\text { demonstrate the benefit of leverag- } \\
\text { ing scientific discourse tags for down- } \\
\text { stream tasks such as claim-extraction } \\
\text { and evidence fragment detection }\end{array}$ & $\begin{array}{l}\text { Develop a sentence-level sequence } \\
\text { tagging model to label discourse } \\
\text { types for each sentence in a para- } \\
\text { graph }\end{array}$ & \\
\hline
\end{tabular}

